$\mathbb{T}$ periodica polytechnica

Chemical Engineering

$5 4 / 2 ( 2 0 1 0 ) 5 7 \longdiv { 6 2 }$

doi: 10.3311/pp.ch.2010-2.01

web: http://www.pp.bme.hu/ch

(c) Periodica Polytechnica 2010

RESEARCH ARTICLE

\section{Liquid-liquid extraction technique for purification of Egyptian WET process phosphoric acid}

\author{
Ali Akl Magda ${ }^{1}$ / Mohammed Youssef Abdul Fatah / Mohammed Ali Mohsen / \\ Ibraheim Amin Mostafa \\ Received 2009-10-10
}

\begin{abstract}
High grade phosphoric acid can be obtained using liquidliquid extraction technique. Different organic solvents were investigated, separately or in mixture, viz. butanol, hexanol, octanol and a mixture of tributylphosphate plus butanol. Among these solvents, n-octanol proved to be the most efficient and selective. The effects of organic solvent concentration, organic/aqueous $(O / A)$ phase ratio, temperature, shaking time and phosphoric acid concentration on $\mathrm{P}_{2} \mathrm{O}_{5}$ extraction were studied. The temperature has a slight positive effect and the extraction was enhanced by increasing $\mathrm{P}_{2} \mathrm{O}_{5}$ and octanol concentrations and with the increase of organic/aqueous phase ratio. The McCabe Thiele extraction equilibrium curve showed that an overall extraction yield of more than $80 \%$ could be reached over three stages from aqueous solutions. Scrubbing and stripping were also investigated. Scrubbing of the loaded organic acid was done using pure phosphoric acid while stripping of $\mathrm{H}_{3} \mathrm{PO}_{4}$ was successfully performed using doubly distilled water (DDW). For $9.2 \mathrm{M} \mathrm{H}_{3} \mathrm{PO}_{4}, 99.90 \%$ of iron, $97.99 \%$ of fluoride and $99.99 \%$ of manganese were removed whereas complete removal of copper, cadmium and zinc was attained.
\end{abstract}

\section{Keywords}

Liquid-liquid extraction · purification $\cdot$ phosphoric acid

\section{Ali Akl Magda ${ }^{1}$}

Department of Chemistry, Mansoura University, P.O. Box 70, Mansoura, Egypt e-mail:magdaak1@yahoo.com

\section{Mohammed Youssef Abdul Fatah}

Department of Chemistry, Mansoura University, 355166, P.O. Box 70, Mansoura, Egypt

\section{Mohammed Ali Mohsen}

Ibraheim Amin Mostafa

Egypt Nuclear Materials Authority, Cairo, Egypt

\section{Introduction}

Wet process phosphoric acid (WPA) contains beside solids and organic matters, many impurities [1]. There has been a wide interest over the last few years to develop a process for the purification of commercial WPA. Many solvents were tried but aliphatic alcohols have the advantages of being cheap, easy to use, separate quickly and do not pollute the food grade. Elimination of cadmium from WPA was studied by Nazari et. al, [2]. Cadmium (Cd) is a toxic heavy metal which can be found in trace quantities $(<100 \mathrm{ppm})$ in phosphate rocks. In the experimental studies described, Cd was removed from WPA by solvent extraction, using amine extractants, notably "Alamine 336" as a tertiary amine extractant. In batch tests, Cd extraction from WPA under optimal conditions was calculated as 74 $\pm 2.54 \%$ (95\% confidence limit). It was concluded that the organic phase, containing $1 \%$ (vol) Alamine $336+1.5 \%$ (vol) isododecanol in kerosene, has good stability and a high efficiency for Cd removal from WPA. Mccullough [3] reported that Occidental Oil developed a process to extract $\mathrm{P}_{2} \mathrm{O}_{5}$ from WPA by liquid-liquid extraction using n-heptanol. It was possible to remove $97 \%$ of the metals and $82 \%$ of the fluoride. The factors affecting the extraction of $\mathrm{H}_{3} \mathrm{PO}_{4}$ by heptanol including temperature and mixing time on the distribution ratio were investigated [4]. The concentration of n-heptanol had a positive effect on the extraction so the solvent was used without dilution. However, the extraction of uranium and heavy metals was negligible while extraction of fluorine and iron was relatively small. Purification of WPA with mixtures of methyl isobutyl ketone (MIBK) and tributyl phosphate (TBP) was also investigated [5]. Greatest recovery of $\mathrm{P}_{2} \mathrm{O}_{5}$ was obtained for MIBK percentage of $55 \%$. The phase diagram of the ternary system $\mathrm{H}_{3} \mathrm{PO}_{4}$-water-optimal solvent was determined. Abdalbake et al. [6], studied the precipitation of $\mathrm{Cd}$, As and sulfate ions. The results showed that the yield of precipitation of sulfate ion increases by increasing the concentration of barium carbonate and temperature. The precipitation of arsenic increases by increasing the concentration of sodium sulfide and temperature. The precipitation of cadmium was better under ambient temperature by sodium sulfide. The

\footnotetext{
${ }^{1}$ To whom correspondence should be addressed.
} 
purification of commercial $\mathrm{H}_{3} \mathrm{PO}_{4}$ from metallic impurities using TBP was studied [7]. About $90 \%$ of $\mathrm{P}_{2} \mathrm{O}_{5}$ in $9.2 \mathrm{M} \mathrm{H}_{3} \mathrm{PO}_{4}$ could be extracted in three stages using 2.55 TBP in kerosene at room temperature. Purification of WPA by solvent extraction with MIBK at $40{ }^{\circ} \mathrm{C}$ was studied [8]. The distribution of the main components $\left(\mathrm{H}_{3} \mathrm{PO}_{4}, \mathrm{H}_{2} \mathrm{O}\right.$ and MIBK) and the major impurities $\left(\mathrm{Ca}^{2+}, \mathrm{Mg}^{2+}, \mathrm{Al}, \mathrm{Fe}, \mathrm{SO}_{4}^{2-}, \mathrm{F}^{-}\right)$between the conjugated phases was systematically studied. The expression of phase compositions on an impurity- free basis enabled to compute the characteristics of $\mathrm{H}_{3} \mathrm{PO}_{4}$ counter current multistage extraction using the McCabe-Thiele method. The electroextraction of mineral impurities from phosphoric acid was achieved by electrodeionization process (EDI) combining ion-exchange membranes (IEM) and textiles (IET) [9]. The purification of pre-concentrated up to $80 \mathrm{wt} \% \mathrm{H}_{3} \mathrm{PO}_{4}$ phosphoric acid (PA) obtained from Kola apatite in one of the Polish plants by the wet processing route was carried out by sulphate precipitation [10], desorption of volatile components $\left(\mathrm{SiF}_{4}, \mathrm{HF}\right)$ and liquid-liquid extraction method using 4-methyl-2-pentanone (MIBK). WPA manufactured using wet process has been purified by minimizing the iron, cadmium, copper and fluoride content. Bentonite clay is found suitable for removal of humic acids and suspended materials from crude phosphoric acid [11].

The aim of the present work is to study the efficiency of noctanol in kerosene as an extractant for $\mathrm{H}_{3} \mathrm{PO}_{4}$ from the wet processed phosphoric acid and to determine the role of the different conditions and parameters contributing to the extraction process. Specification of phosphoric acid before and after solvent extraction and determination of the extraction diagram represent also a major aim of the present investigation.

\section{Experimental}

\subsection{Materials and measurements}

Different organic solvents were investigated viz., butanol, hexanol, octanol and a mixture of tributylphosphate plus butanol. Normal octanol (BDH)/England with $99 \%$ purity was used. Commercial WPA $\left(\mathrm{P}_{2} \mathrm{O}_{5}=44.0 \%, \mathrm{Fe}=2.6 \%, \mathrm{Cu}=\right.$ $0.0012 \%, \mathrm{Cd}=0.001 \%, \mathrm{~F}=0.7 \%$ ) was supplied from AbuZaabal Co., Cairo, Egypt. Abu Tartur bentonite was used. All chemicals and reagents were of A.R. grade and used without further purification. $\mathrm{Fe}, \mathrm{Cd}$ and $\mathrm{Cu}$ were determined by $\mathrm{GBC}$ 932- AAS. The fluoride content was determined by ion selective electrode, a Genway, model $3330 \mathrm{pH}$ meter equipped with Orion model 94-09 BN fluoride electrode. $\mathrm{P}_{2} \mathrm{O}_{5}$ was determined spectrophotometrically. The concentration of $\mathrm{P}_{2} \mathrm{O}_{5}$ in the solvent was calculated from the material balance. The yield was calculated from the equation:

$$
\text { Yield }(\mathrm{Y} \%)=\frac{\left[\mathrm{P}_{2} \mathrm{O}_{5}\right]_{\text {feed acid }}-\left[\mathrm{P}_{2} \mathrm{O}_{5}\right]_{\text {raffinate }}}{\left[\mathrm{P}_{2} \mathrm{O}_{5}\right]_{\text {feed acid }}} \times 100
$$

The distribution ratio $(D)$ was calculated from the equation:

$$
D=\frac{\text { Total concentration of } \mathrm{P}_{2} \mathrm{O}_{5} \text { in organic phase }}{\text { Total concentration of } \mathrm{P}_{2} \mathrm{O}_{5} \text { in aqueous phase }} \times \frac{\text { volume of aq. }}{\text { volume of org. }}
$$

\subsection{Analytical Procedures}

\subsubsection{Acid pre-treatment}

Crude phosphoric acid was mixed with bentonite $(11.67 \mathrm{~g} / \mathrm{l})$ for $30 \mathrm{~min}$. and the acid was left to settle down. Polycrylamide type $(0.5 \mathrm{mg} / \mathrm{l})$ as a flocculating agent was added to enhance the settlement of the suspended materials.

\subsubsection{Production of partially purified phosphoric acid}

Pre-treated phosphoric acid was partially purified [11] before applying solvent extraction technique to decrease the concentration of fluoride and iron by precipitation using $5.9 \mathrm{~g} / / \mathrm{L} \mathrm{SiO}_{2}+$ $10.5 \mathrm{~g} / \mathrm{L} \mathrm{Na} \mathrm{CO}_{3}$ followed by addition of $26.7 \mathrm{~g} / \mathrm{L} \mathrm{K}_{2} \mathrm{SO}_{4}$.

\subsubsection{Extraction process of $\mathrm{P}_{2} \mathrm{O}_{5}$}

The extraction process of $\mathrm{P}_{2} \mathrm{O}_{5}$ was carried out from different concentrations of WPA. Different organic solvents were investigated, separately or in mixture, viz. butanol, hexanol, octanol and a mixture of tributylphosphate plus butanol. The different parameters investigated were: solvent concentration (0.63-6.31 $\mathrm{M})$, temperature $\left(25-60^{\circ} \mathrm{C}\right)$, shaking time (1-30 min.) and organic to aqueous (O / A) phase ratio (1-6). Different volumes of organic $(10,20,30,40,50$ and $60 \mathrm{~mL})$ and aqueous phases $(10$ $\mathrm{mL}$ ) were equilibrated for $10 \mathrm{~min}$. under vigorous shaking in a thermostated water bath. After phase separation, the concentration of $\mathrm{P}_{2} \mathrm{O}_{5}$ in the aqueous phase before and after extraction was determined. The extraction percent $\left(\mathrm{E}_{\text {extn }}\right.$ ' \%) were calculated, Eq. (3):

$$
\left(\mathrm{E}_{\text {extn }}^{\prime} \%\right)=\frac{100 D}{D+V_{\mathrm{aq}} / V_{\mathrm{org}}}
$$

\subsubsection{Scrubbing process}

The organic extract was preferably scrubbed (washed) with aqueous pure phosphoric acid. In this step, a large portion of undesirable impurities could be removed from the organic extract if present. The factors affecting washing efficiency were studied.

\subsubsection{Stripping investigation}

The stripping investigations were carried out to determine the best condition that can successfully strip $\mathrm{H}_{3} \mathrm{PO}_{4}$ from the organic phase. The effect of shaking time and organic to aqueous ratio were studied.

The aqueous and organic phases were stirred for 5 minutes and then allowed to settle for 20 minutes to separate in a funnel. The concentration of the acid was measured spectrophotometrically.

\section{Results and discussion}

3.1 Liquid-liquid extraction of $\mathrm{P}_{2} \mathrm{O}_{5}$ from wet process phosphoric acid

Different organic solvents were investigated, separately or in mixture, viz. butanol, hexanol, octanol and a mixture of triphosphate plus butanol. Among these solvents, n-octanol proved to be the most efficient and selective. The acid obtained 
by extraction with n-octanol contains the least impurities, (Table (1). The obtained results revealed, also, that the extraction efficiencies of the used solvents could be arranged as: n-octanol $>$ tributylphosphate/butanol $>$ n-hexanol $>$ n-butanol. Further investigations were performed using $\mathrm{n}$ - octanol.

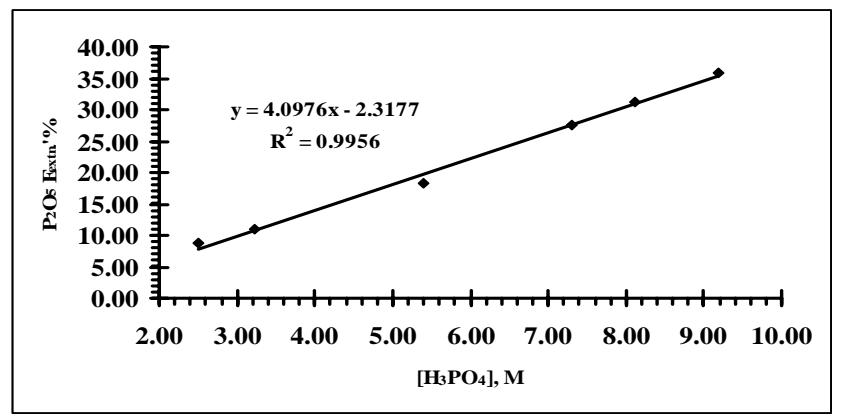

Fig. 1. Effect of phosphoric acid concentration on $\mathrm{E}_{\text {extn. }}$ ' $\%$ of $\mathrm{P}_{2} \mathrm{O}_{5}$

\subsubsection{Effect of phosphoric acid concentration}

The effect of phosphoric acid concentration on $\mathrm{E}_{\text {extn }}$ '\% was investigated (Fig. 11). The extraction of $\mathrm{P}_{2} \mathrm{O}_{5}$ from partially purified phosphoric acid within the concentration range 3.99-9.20 $\mathrm{M}$ was determined at room temperature, shaking time of $10 \mathrm{~min}$. and $\mathrm{O} / \mathrm{A}$ phase ratio equal to 1 . The results reveal that $\mathrm{E}_{\text {extn }}$ ' $\%$ continuously increases with the increase of the acid concentration to reach $35.80 \%$. The high values of $\mathrm{E}_{\text {extn }}$ \% from $9.2 \mathrm{M}$ $\mathrm{H}_{3} \mathrm{PO}_{4}$ refer to the validity of the present method. In the extracted species, the protons of the acid may form a hydrogen bond with an oxygen atom and thus its extraction is quite reasonable. The oxygen atom of the octanol molecule may combine with the hydrogen atoms of the hydrate water molecule which combines with the proton of the strong acid through its oxygen. The co-extraction of strong acid together with the trisolvated phosphoric acid should occur by a hydrogen bond formation between the phosphoryl oxygen of phosphoric acid and the proton of the strong acid. In the aqueous phase the phosphoryl oxygen and the three protons of the phosphoric acid should be hydrogen bonded with water molecules and even after the removal of water molecules are removed by the salvation with octanol, the hydration on the phosphoryl oxygen may continue leading to a significant improvement of $\mathrm{H}_{3} \mathrm{PO}_{4}$ extraction. In the aqueous phase, a proton dissociated from a strong acid should combine with the oxygen atom of water molecule. However, the proton should also be able to combine with the phosphoryl oxygen atom of phosphoric acid solvated with alcohol in the organic phase by forming a hydrogen bond.

\subsubsection{Effect of solvent concentration}

The extraction of $\mathrm{P}_{2} \mathrm{O}_{5}$ from partially purified phosphoric acid $(9.20 \mathrm{M})$ was studied at room temperature. The results (Fig. 2) show that within the concentration range (0.63-6.31 M) of the octanol, $\mathrm{E}_{\mathrm{extn}}$ ' $\%$ increases with the increase of octanol concentration.

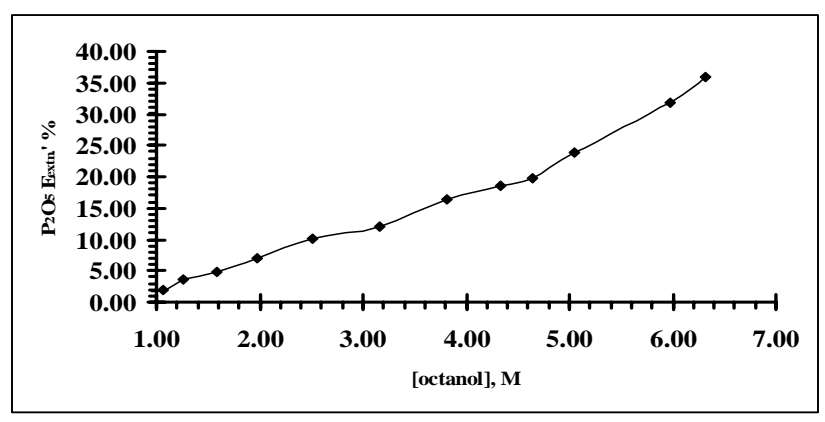

Fig. 2. Effect of octanol concentration on $\mathrm{E}_{\text {extn. }}$. $\%$ of $\mathrm{P}_{2} \mathrm{O}_{5}$

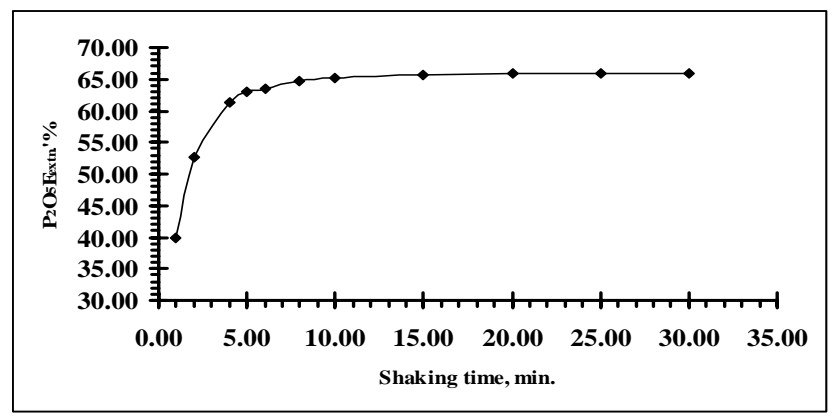

Fig. 3. Effect of shaking time on $\mathrm{E}_{\text {extn }}$.' $\%$ of $\mathrm{P}_{2} \mathrm{O}_{5}$.

\subsubsection{Effect of shaking time}

Shaking time is an important factor in determining the efficiency of liquid-liquid extraction processes which involve mass transfer between two liquids. The effect of shaking time was investigated between 1.0 and $30.0 \mathrm{~min}$. under the following conditions: $\mathrm{H}_{3} \mathrm{PO}_{4}=9.20 \mathrm{M}\left(\mathrm{O} / \mathrm{A}=1: 5\right.$ and $\left.\mathrm{T}=25^{\circ} \mathrm{C}\right)$. The results are graphically presented in Fig. 3 . Evidently the extraction was found to be rapid indicating that diffusion which is influenced by stirring has very little influence on extraction

\subsubsection{Effect of organic to aqueous (O/A) phase ratio}

The effect of changing $\mathrm{O} / \mathrm{A}$ phase ratio between 1.0 and 6.0 on, $\mathrm{E}_{\text {extn }}$ ' $\%$ of $\mathrm{P}_{2} \mathrm{O}_{5}$ from concentrated phosphoric acid $(9.20$ $\mathrm{M}$ ), was investigated. Fig. 4 depicts that $\mathrm{E}_{\text {extn }}{ }^{\prime} \%$ of $\mathrm{P}_{2} \mathrm{O}_{5}$ increases by increasing the $\mathrm{O} / \mathrm{A}$ phase ratio.

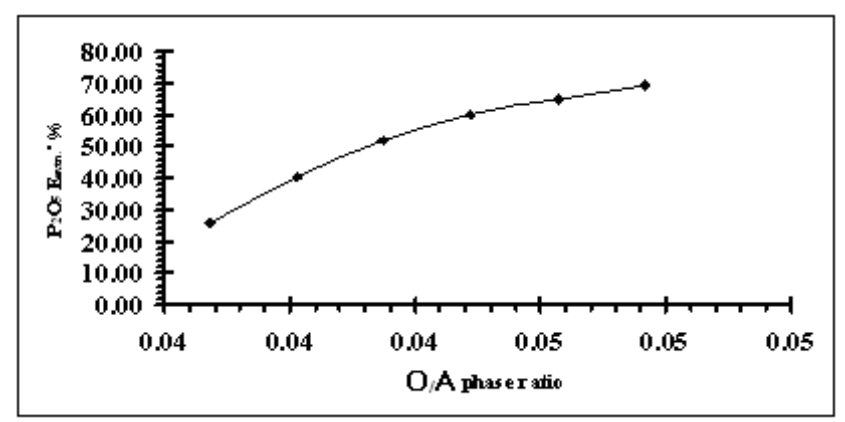

Fig. 4. Effect of organic to aqueous phase ratio(O/A) on $\mathrm{E}_{\text {extn. }}$. $\%$ of $\mathrm{P}_{2} \mathrm{O}_{5}$

\subsubsection{Effect of temperature}

The extraction of $\mathrm{P}_{2} \mathrm{O}_{5}$ from the partially purified phosphoric acid $(9.20 \mathrm{M})$ was investigated at different temperature between 278 and 333K (Fig. 5). The O/A phase ratio was 1:5 and 
Tab. 1. Chemical specifications of different types of phosphoric acid

\begin{tabular}{lcccccc}
\hline \multirow{2}{*}{ Type of Phosphoric acid } & \multicolumn{7}{c}{ Element, ppm } \\
\cline { 2 - 7 } & $\mathrm{Fe}$ & $\mathrm{F}$ & $\mathrm{Cu}$ & $\mathrm{Cd}$ & $\mathrm{Zn}$ & $\mathrm{Mn}$ \\
\hline Crude WPA & 40560.0 & 11230.0 & 18.6 & 15.0 & 620.0 & 1860.0 \\
Partially purified WPA & 10140.0 & 499.2 & 18.6 & 15.0 & 620.0 & 1860.0 \\
Finally produced WPA using butanol & 525.00 & 100.00 & N.D & 0.050 & 25.80 & 2.341 \\
Finally produced WPA using hexanol & 80.00 & 20.00 & N.D & N.D & 1.00 & N.D \\
Finally produced WPA using octanol & 10.00 & 10.00 & N.D & N.D & N.D & 0.023 \\
Finally produced WPA using Butanol+TPB & 12.00 & 8.00 & N.D & N.D & N.D & N.D \\
\hline N.D.: not detected & & & & & &
\end{tabular}

the shaking time was 10.00 min. It is shown that $E_{\text {extn }}$ ' \% of $\mathrm{P}_{2} \mathrm{O}_{5}$ increased from 64.00 to $70.11 \%$. Fig. 5 shows also that the increase of $\mathrm{E}_{\text {extn }}, \%$ is less pronounced upon increasing the temperature from 25 to $40{ }^{\circ} \mathrm{C}$. This is interesting when energy consumption either for cooling or heating is considered.

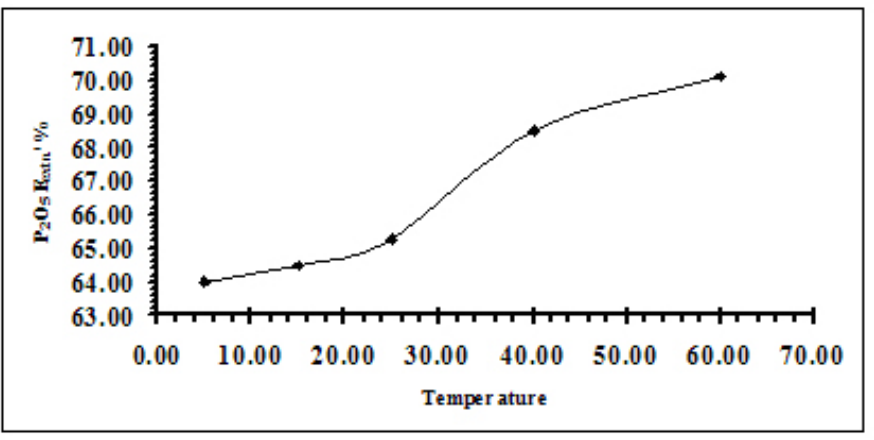

Fig. 5. Effect of temperature on $\mathrm{E}_{\text {extn }}$. $\%$ of $\mathrm{P}_{2} \mathrm{O}_{5}$.

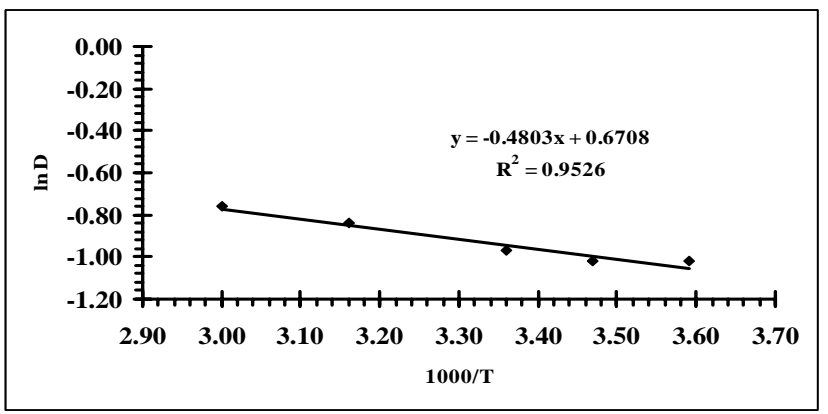

Fig. 6. Effect of $\ln \mathrm{D}$ as a function of $1000 / \mathrm{T}$

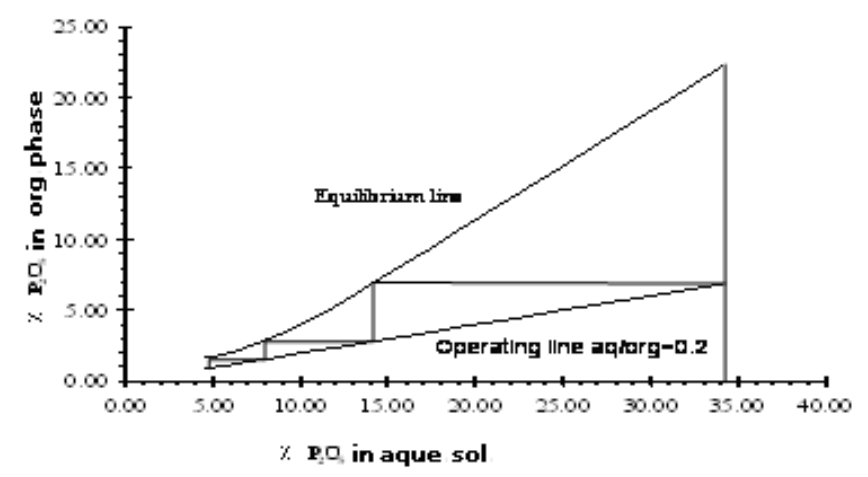

Fig. 7. McCabe Thiele Diagram for the extraction of $\mathrm{P}_{2} \mathrm{O}_{5}$ using octanol

The results are also plotted in Fig. 6 6in the form of $\ln \mathrm{D}$ versus
$1000 / \mathrm{T}{ }^{\circ} \mathrm{K}$. The result fits a straight line equation with a slope value -0.4803 . The relation between the equilibrium constant $K$ and the temperature is given by Vant Hoff equation:

$$
d \ln K / d T=\Delta H / R \cdot T^{2}
$$

By integration,

$$
\ln K=(-\Delta H / R)(1 / T)
$$

And since the distribution ratio $D$ is related by definition to the equilibrium constant $K$, the previous equation could be written:

$$
\ln D=(-\Delta H / R)(1 / T)
$$

It was possible to calculate the enthalpy change $(\Delta \mathrm{H})$. This value is $3.9932 \mathrm{KJ} / \mathrm{mol}$. The positive values of $\Delta \mathrm{H}$ refer to the positive effect of extraction temperature.

\subsubsection{McCabe Thiele Diagram for extraction of phosphoric acid}

Considering the optimum conditions for $\mathrm{P}_{2} \mathrm{O}_{5}$ extraction from 9.20 M partially purified phosphoric acid using $6.31 \mathrm{M}$ octanol, shaking time of $10.00 \mathrm{~min}$ and at room temperature, wet phosphoric acid extraction equilibrium curve (Fig. 7), was used to calculate the number of counter current stages required to achieve about $87.07 \%$ extraction yield at $25{ }^{\circ} \mathrm{C}$.

The operating line was drawn according to the concentration of the feed acid $(60.32 \mathrm{wt} \%)$. The concentration of the raffinate acid is about $7.80 \mathrm{wt} \%$ and the slope of operating line equals the ratio of $\mathrm{A} / \mathrm{O}$ phase 1:5.

\subsubsection{Chemical equilibrium for the solvent extraction pro- cess}

It has been already mentioned that scrubbing and stripping process are more or less time independent. Extraction process on the other hand was found to be time dependent where significant increase in $\mathrm{E}_{\text {extn. }}$ ' \% was observed with the increase of shaking time; this stimulated the study of the kinetics of the extraction process. The distribution coefficient $D$ was determined for octanol at the optimum O/A phase ratio. This coefficient was found to be related to the solvent concentration when the concentration of the acid was constant $(9.20 \mathrm{M})$. Evidently, straight 
line was obtained for octanol at $\mathrm{O} / \mathrm{A}$ phase ratio $=5$ when $\log$ D was plotted versus log [octanol], (Fig. 8). The slope of this straight line was 1.649 .

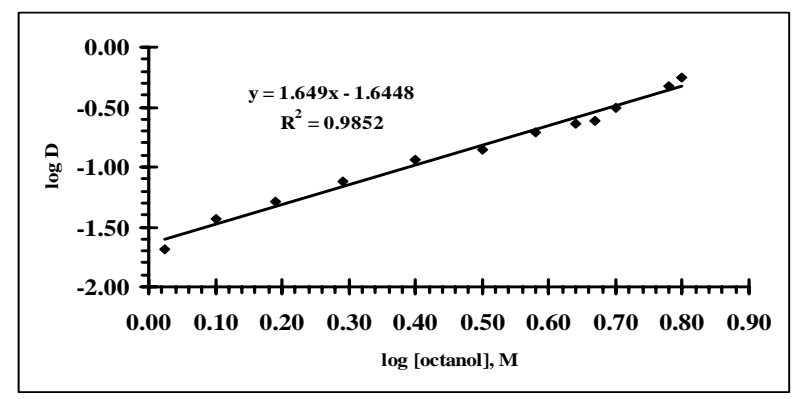

Fig. 8. $\log \mathrm{D}$ as a function of the $\log$ octanol concentration

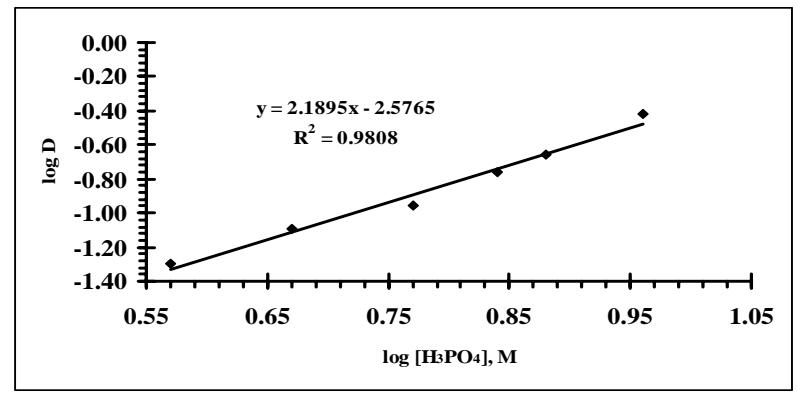

Fig. 9. $\log \mathrm{D}$ as a function of the $\log \mathrm{H}_{3} \mathrm{PO}_{4}$ concentration

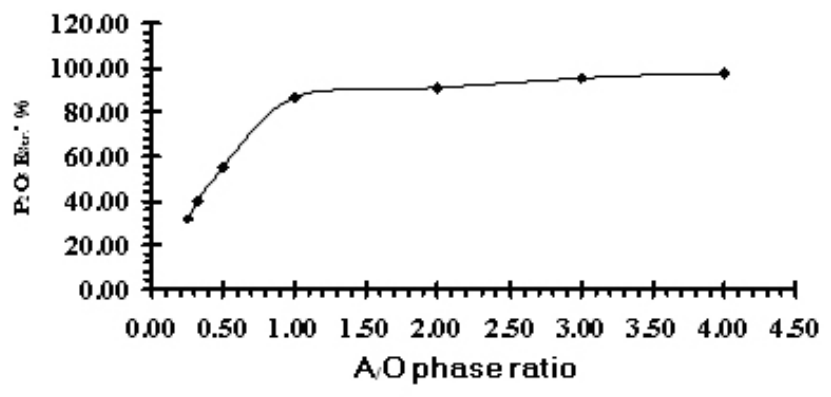

Fig. 10. Effect of organic to aqueous phase ratio on $\mathrm{E}_{S t r . .} \%$ of $\mathrm{P}_{2} \mathrm{O}_{5}$

The extraction of phosphoric acid from the aqueous phase to the solvent at its optimum $\mathrm{O} / \mathrm{A}$ ratio was found also to depend on the concentration of the acid when the solvent concentration was kept constant. Fig. 9 shows $\log D$ as a function of $\log \left[\mathrm{H}_{3} \mathrm{PO}_{4}\right]$. The obtained straight line was shown with a slope of 2.190 .

Assuming that Eq. (1) represents the extraction equilibrium

$$
1.33 \mathrm{H}_{3} \mathrm{PO}_{4 \text { (aq.) }}+\text { octanol }_{(\text {org. })} \longleftrightarrow \operatorname{octanol}\left(\mathrm{H}_{3} \mathrm{PO}_{4}\right)_{1.33 \text { (org.) }}
$$

The values of the equilibrium constant of extraction $K_{\text {extn }}$, can be obtained from Eq. 8 :

$$
K_{\text {extn }}=\left[\operatorname{octanol}\left(\mathrm{H}_{3} \mathrm{PO}_{4}\right)_{1.33}\right]_{(\text {org. })} /[\text { octanol }]_{\text {org. }}\left[\mathrm{H}_{3} \mathrm{PO}_{4}\right]_{(\text {aq. })}^{1.33}
$$

The logarithm form of Eq. (8) is

$\log K_{\text {extn }}=\log \left[\right.$ Oct. $\left.\left(\mathrm{H}_{3} \mathrm{PO}_{4}\right)_{x}\right]-1.33 \log \left[\mathrm{H}_{3} \mathrm{PO}_{4}\right]-$ Log$[$ Oct. $]$
From Eq. (9), the average extraction equilibrium constant for octanol was determined to be 0.04 mole $^{-1.33}$.

\subsection{Scrubbing process}

The organic extract may still have impurities. Scrubbing of the organic extract is conventionally carried out using an aqueous solution of pure phosphoric acid. Because the scrubbing process is an important step towards getting high grade product, the optimum conditions should be determined by studying the effect of the factors controlling the efficiency of this process.

Tab. 2. Physical properties and impurities content of the different grades of

\begin{tabular}{|c|c|c|c|c|}
\hline \multirow{3}{*}{ Constituent } & \multicolumn{4}{|c|}{ Phosphoric acid grades } \\
\hline & \multicolumn{4}{|c|}{ Concentration } \\
\hline & TGA & FGA & PGA & AGA \\
\hline $\mathrm{H}_{3} \mathrm{PO}_{4} \% \mathrm{w} / \mathrm{w}$ & $85.0 \%$ & $85.0 \%$ & $85.0 \%$ & $86.0 \%$ \\
\hline $\mathrm{P}_{2} \mathrm{O}_{5} \% \mathrm{w} / \mathrm{w}$ & $61.6 \%$ & 61.6 & $61.6 \%$ & 62.0 \\
\hline Density at $25^{\circ} \mathrm{C}$ & 1.6 & 1.6 & 1.6 & 1.7 \\
\hline \multicolumn{5}{|c|}{ Concentration, ppm } \\
\hline $\mathrm{Fe}$ & 20.0 & 20.0 & 20.0 & 15.0 \\
\hline $\mathrm{F}^{-}$ & 100.0 & 10.0 & 10.0 & 10.0 \\
\hline $\mathrm{NO}_{3}^{-}$ & 20.0 & 5.0 & 5.0 & 5.0 \\
\hline $\mathrm{SO}_{4}^{-}$ & 200.0 & 100.0 & 50.0 & 20.0 \\
\hline $\mathrm{Cu}$ & 20.0 & 10.0 & 5.0 & 5.0 \\
\hline $\mathrm{Pb}$ & 10.0 & 5.00 & 1.0 & 3.0 \\
\hline
\end{tabular}
phosphoric acid

\subsubsection{Effect of washing acid concentration}

The effect of the concentration of pure phosphoric acid used for washing was studied at $25{ }^{\circ} \mathrm{C}$ in the range of $7.98 \mathrm{M}$ for octanol. The loaded octanol to washing acid ratio was 1.00 and shaking time was $5.00 \mathrm{~min}$. preliminary experiments have shown that the shaking time is not a determining factor in the scrubbing process. The results revealed that by increasing the acid wash concentration, the $\mathrm{P}_{2} \mathrm{O}_{5}$ transferring from organic extract phase to wash acid phase decreased reaching to zero at 7.61 $\mathrm{M}$ acid wash concentration.

\subsubsection{Effect of organic extract to wash acid ratio}

A series of experiments was performed with different organic extract to wash acid ratios ranging from 0.50 to 4.00 at $25{ }^{\circ} \mathrm{C}$ and shaking time $5 \mathrm{~min}$. The experiments were conducted using 7.61 $\mathrm{M}$ acid wash concentration. The results revealed that the transfer of $\mathrm{P}_{2} \mathrm{O}_{5}$ from washing acid to organic extract phase increases by increasing the organic extract to wash acid ratio reaching to a limiting value at organic/acid wash $=1$ beyond which the transfer of $\mathrm{P}_{2} \mathrm{O}_{5}$ from the organic phase to the washing acid phase increases.

\subsection{Stripping process}

The re-extraction of $\mathrm{P}_{2} \mathrm{O}_{5}$ from the loaded octanol was investigated using DDW to obtain diluted phosphoric acid. Higher pure concentrated phosphoric was thereafter obtained by evaporation. 
Tab. 3. Chemical composition of wet process phosphoric acid before and after purification process

\begin{tabular}{|c|c|c|c|c|c|c|}
\hline \multirow{2}{*}{$\begin{array}{l}\text { Type of Phosphoric } \\
\text { acid }\end{array}$} & \multicolumn{6}{|c|}{ Element, ppm } \\
\hline & $\mathrm{Fe}$ & $\mathbf{F}^{-}$ & $\mathrm{Cu}$ & Cd & $\mathrm{Zn}$ & Mn \\
\hline Crude WPA & 40560.0 & 11230.0 & 18.6 & 15.0 & 620.0 & 1860.0 \\
\hline Partially purified WPA & 10140.0 & 499.2 & 18.6 & 15.0 & 620.0 & 1860.0 \\
\hline $\begin{array}{l}\text { Finally produced WPA } \\
\text { using TOA [12] }\end{array}$ & 600.0 & 100.0 & 10.0 & 10.0 & 250.0 & 425.0 \\
\hline $\begin{array}{l}\text { Finally produced WPA } \\
\text { using TBP [7] }\end{array}$ & 435.0 & 90.0 & 3.0 & 0.5 & 50.0 & 70.3 \\
\hline $\begin{array}{l}\text { Finally produced WPA } \\
\text { using octanol }\end{array}$ & 10.0 & 10.0 & N.D & N.D & N.D & 0.023 \\
\hline
\end{tabular}

\subsubsection{Effect of aqueous to organic ratio}

The effect of $\mathrm{A} / \mathrm{O}$ phase ratio on the $\mathrm{P}_{2} \mathrm{O}_{5}$ stripping from loaded octanol has been studied using distilled water at room temperature, while shaking time for $5.00 \mathrm{~min}$. The $\mathrm{A} / \mathrm{O}$ phase ratio was varied from 0.25 to 4.00 . Fig. 10 depicts that upon increasing $\mathrm{A} / \mathrm{O}$ ratio, the $\mathrm{P}_{2} \mathrm{O}_{5}$ stripping efficiency increased to exhibit a maximum at a ratio $=2.0$. Further increase of $\mathrm{A} / \mathrm{O}$ ratio was associated with a very slight increase of $\mathrm{P}_{2} \mathrm{O}_{5}$ stripping.

\subsection{Removal efficiency of impurities from phosphoric acid}

Phosphoric acids are graded according to their physical properties and the concentration of some metallic and non-metallic impurities contained. Four grades are reported in literature. These grades are arranged according to their quality as: technical grade acid TGA $<$ food grade acid FGA $<$ pharmaceutical grade acid PGA $<$ analytical grade acid AGA. Table 2 lists the physical properties and impurities content of these four grades.

Table 2 reveals that the difference in the physical properties is negligible. However, the difference in the impurities content expressed in ppm is pronounced. This was found true when the impurities determined in this investigation for crude acid, partially purified acid and finally produced acid are considered Table 3 .

The data listed in Table 3 indicates that the finally produced acids are by far more superior compared with any of the grades reported in literature. Although the finally produced acid obtained in this investigation is more or less of the same grade, the acid obtained by extraction with octanol contains the least impurities.

\section{Conclusion}

Removal of metallic and non-metallic impurities from WPA was investigated by solvent extraction using n-octanol. $\mathrm{P}_{2} \mathrm{O}_{5}$ was extracted from $9.2 \mathrm{M} \mathrm{H}_{3} \mathrm{PO}_{4}$ in three stages at $25{ }^{\circ} \mathrm{C}$ with organic/aqueous phase ratio equal 1:5, while the shaking time was $10 \mathrm{~min}$. The percentage of extraction was $87.07 \%$.

Scrubbing of the organic extract was made by shaking the loaded octanol with pure phosphoric acid and 7.61 M.

Stripping of the acid from the organic phase with distilled water at room temperature was made from a system of or- ganic/aqueous phase ratio $=2$. The finally produced WPA was found to be highly pure compared with all the acid grades reported in literature. The concentrations of $\mathrm{Fe}, \mathrm{F}^{-}$and $\mathrm{Mn}$ were determined in the finally produced phosphoric acid to be 10,10 and $0.023 \mathrm{ppm}$ respectively. The concentrations of $\mathrm{Cu}, \mathrm{Cd}$ and $\mathrm{Zn}$ were too low to be determined.

\section{References}

1 Shlewit H, Khorfan S, Purification of phosphoric acid by solvent extraction with TBP/kerosene, Solvent extraction research and development 9 (2002), 59-68.

2 Nazari K, Ghadiri A, Babaie H, Elimination of cadmium from wet process phosphoric acid with Alamine 336, Miner. Engin. 18 (2005), 1233-1238.

3 Mccullough J F, Chem. Eng. 6 (1976), 101.

4 Khorfan S, Shino O, Wahoud A, Extraction of $\mathrm{H}_{3} \mathrm{PO}_{4}$ from wet phosphoric acid by $n C 4-n C 7$ alcohols, Perio. Polytech. Chem. Eng. 45/2 (2001), 139-148.

5 Hannachi A, Diamonta H, Chaker C, Abdelhamid R, Purification of wet process phosphoric acid by solvent extraction with TBP and MIBK mixtures, Sep. and Purif. Techn. 55 (2007), 212-216.

6 Abdalbake M, Shino 0, Removing the cadmium, arsenic and sulfate ions from wet process phosphoric acid, Period. Polytech., Chem. Eng. 48 (2004), no. 1, 63-71.

7 Abu-Raia A, Purification of Commercial Phosphoric Acid Using Organic Solvents, 2006. M.Sc Thesis.

8 Feki M, Stambouli M, Pareau D, Ayedi HF, Study of The Multicomponent System Wet Process Phosphoric Acid-Methyl Isobutyl Ketone At 403oC Phase Equilibria And Extraction Performances, Chem. Engin. 88 (2002), 7180.

9 Myriam Ben Chehida Elleuch, Mohamed Ben Amor, Pourcelly G, Phosphoric acid purification by a membrane process: Electrodeionization on ion-exchange textiles, Separation and Purification Technology 51 (2006), 285-290.

10 Kijkowska R, Pawlowska-Kozinska D, Kowalski Z, Jodko M, Wzorek $\mathbf{Z}$, Wet-process phosphoric acid obtained from Kola apatite. Purification from sulphates, fluorine, and metals, Sep. and Purif. Techn. 28 (2002), 197-205.

11 Ahmed El-Asmy A, Serag H M, Mahdy M A, Amin M I, Purification of phosphoric acid by minimizing iron, copper, cadmium and fluoride, Sep. and Purif. Techn. 61 (2008), 287-291.

12 Abd-Elkhalek A, Ali M M, Fawzy A, Clarification of wet process phosphoric acid. M.Sc Thesis. 